\title{
Optimal cumulative dose of cisplatin for concurrent chemoradiotherapy among patients with locally advanced nasopharyngeal carcinoma: a multicenter analysis in Thailand
}

Nuttapong Ngamphaiboon ( $\square$ Nuttapong.nga@mahidol.ac.th )

Mahidol University Faculty of Medicine Ramathibodi Hospital https://orcid.org/0000-0002-6535-6345

Arunee Dechaphunkul

Prince of Songkla University Faculty of Medicine

Jiraporn Setakornnukul

Mahidol University Faculty of Medicine Siriraj Hospital

Tanadech Dechaphunkul

Prince of Songkla University Faculty of Medicine

Rungarun Jiratrachu

Prince of Songkla University Faculty of Medicine

Bhoom Suktitipat

Mahidol University Faculty of Medicine Siriraj Hospital

Chuleeporn Jiarpinitnun

Mahidol University Faculty of Medicine Ramathibodi Hospital

Poompis Pattaranutaporn

Mahidol University Faculty of Medicine Ramathibodi Hospital

Pongwut Danchaivijitr

Mahidol University Faculty of Medicine Siriraj Hospital

Research article

Keywords: Nasopharyngeal carcinoma, cisplatin, chemoradiotherapy, cumulative dose, nephrotoxicity

Posted Date: May 1st, 2020

DOI: https://doi.org/10.21203/rs.3.rs-25252/v1

License: (c) (i) This work is licensed under a Creative Commons Attribution 4.0 International License.

Read Full License 
Version of Record: A version of this preprint was published at BMC Cancer on June 3rd, 2020. See the published version at https://doi.org/10.1186/s12885-020-07024-8. 


\section{Abstract}

\section{Introduction}

Chemoradiotherapy (CRT) with high cumulative doses (CDs) of cisplatin has been considered the standard of care for locally advanced nasopharyngeal carcinoma (LA-NPC). However, given most patients' inability to tolerate high CDs due to cisplatin-related toxicities, the optimal CD of cisplatin during CRT remains undetermined.

\section{Methods}

Patients with LA-NPC who received CRT with cisplatin between 2007 and 2017 were identified through the Thai head and neck cancer multicenter database and then categorized according to cisplatin $\mathrm{CD}\left(\mathrm{mg} / \mathrm{m}^{2}\right)$ received. All complications and cisplatin-related toxicities during CRT were recorded.

\section{Results}

We identified 779 LA-NPC patients receiving low (£150; $n=97)$, intermediate (151-250; $n=411)$, and high $(>250 ; n=271)$ CDs of cisplatin. Low CD patients had significantly lower mean actual radiation dose $(p<0.001)$ and more radiotherapy delay $(p=0.010)$, while intermediate CD patients had the least hospitalization ( $p<0.001)$. Overall, $39.3 \%$ of the patients experienced cisplatin-related toxicity, which was associated with poor overall survival (OS) $(p=0.001)$. Acute kidney injury was observed in $7 \%$ in all patients, which was highest among low CD patients (15.5\%; $\mathrm{p}=0.002)$. Intermediate CD patients had significantly longer median OS than the low and high groups (64 vs. 49.8 vs. 53.2 , respectively; $p=0.015$ ). Univariate, but not multivariate, analysis showed that $C D$ of cisplatin was significantly associated with OS.

\section{Conclusion}

CD of cisplatin during CRT was not an independent prognostic factor for OS. An intermediate CD induced minimal toxicity without compromising survival and should be considered the optimal CD. Nonetheless, a randomized phase 3 study evaluating the optimal $C D$ of cisplatin is warranted.

\section{Introduction}

Nasopharyngeal carcinoma (NPC) is highly endemic to Southern China, Maghreb region of North Africa, parts of the Middle East, and Southeast Asia, including Thailand [1,2]. Epstein-Barr virus (EBV) plays a major role in carcinogenesis. Ninety-six percent of Thai patients with NPC are associated with EBV [3]. Concurrent chemoradiotherapy (CRT) with cisplatin is the standard of care for local advanced NPC treatment [4]. Several phase III clinical studies utilized high-dose cisplatin, either $100 \mathrm{mg} / \mathrm{m}^{2}$ every 3 weeks for three cycles [cumulative dose (CD), $300 \mathrm{mg} / \mathrm{m}^{2}$ ] or $40 \mathrm{mg} / \mathrm{m}^{2}$ weekly for seven cycles (CD, 280 $\mathrm{mg} / \mathrm{m}^{2}$ ), for using concurrently with radiotherapy (RT) [5-8]. However, no study has evaluated the 
optimal cisplatin CD administration during CRT. A post-hoc analysis from a Chinese prospective phase III study of patients with locally advanced NPC (LA-NPC) concurrently receiving weekly cisplatin and radiotherapy (RT) reported a median cisplatin $C D$ of $240 \mathrm{mg} / \mathrm{m}^{2}$, despite protocols requiring a CD of 280 $\mathrm{mg} / \mathrm{m}^{2}$ [9]. Several retrospective studies demonstrated real-world data that majority of patients received less than the standard recommendations for cisplatin $C D\left(280-300 \mathrm{mg} / \mathrm{m}^{2}\right)[8,10-12]$. However, patients receiving a lower cisplatin $C D$ had comparable survival with patients receiving the recommended $C D$. Thus, the lowest efficacious cisplatin CD during CRT remains unidentified.

About $13.6 \%$ patients with cancer treated with cisplatin develop nephrotoxicity, i.e., acute kidney injury (AKI), which is significantly associated with administrated cisplatin dose [13]. Incidences of nephrotoxicity among head and neck cancer patients receiving cisplatin CRT were $30 \%-34 \%$, higher than in those with other cancer types $[14,15]$. Therefore, we evaluated the optimal cisplatin CD for definitive CRT that would maintain efficacy and minimize toxicity among patients with locally advanced NPC in a multicenter setting in Thailand.

\section{Material And Methods}

\section{Patient population}

We identified patients with histologically confirmed LA-NPC who received treatment at the three largest cancer centers in Thailand, Ramathibodi and Siriraj Hospitals, Mahidol University, and Songklanagarind Hospital, Prince of Songkla University, between 2007 and 2017. All medical records were retrospectively reviewed. Patient characteristics, treatments, toxicities, complications, and survival rates were abstracted and recorded in the common electronic case record form of the large multicenter multidisciplinary database for Thai head and neck cancer patients using the REDCap platform. This database was established in 2016 and was funded by the Thailand Grand Challenge Program for Research University Network (RUN) under the Precision Medicine for Cancer project. The present study was approved by the Institutional Ethic Committee.

Patients with LA- NPC who received cisplatin for concurrent CRT were identified from the database. Those who received induction chemotherapy, had distant metastasis at diagnosis, or received non-cisplatin chemotherapy for CRT were excluded. Overall survival (OS), recurrence-free survival (RFS), distant recurrence-free survival (DRFS), and locoregional recurrence-free survival (LRFS) were determined. Death status was validated and confirmed through the Thai Social Security Death Index database.

\section{Cisplatin dose for chemoradiotherapy and its complications}

CD of cisplatin $\left(\mathrm{mg} / \mathrm{m}^{2}\right)$ used during CRT was calculated and classified into low, intermediate, and high. The dose cutoffs were identified using the area under the curve associated with the gold standard for predicting death status. CD of cisplatin during CRT was categorized into low ( $\left.£ 150 \mathrm{mg} / \mathrm{m}^{2} ; \mathrm{n}=97\right)$, intermediate $\left(151-250 \mathrm{mg} / \mathrm{m}^{2} ; \mathrm{n}=411\right)$, and high ( $>250 \mathrm{mg} / \mathrm{m}^{2} ; \mathrm{n}=271$; Supplement 1$)$. The correlation 
between aforementioned dose levels and patient characteristics, RT treatment, treatment tolerability, complications, and survival was then determined.

Acute complications during CRT were defined as experience of any cisplatin or RT interruption, treatment delay ( $>7$ days), hospitalization ( $>24 \mathrm{~h}$ ), and/or discontinuation of cisplatin or RT. Cisplatin-related complications included creatinine clearance (CCr) decline after CRT (calculated using the CockcroftGault formula), AKI [16], acute kidney disease (AKD), defined by (i) GFR $<60 \mathrm{ml} / \mathrm{min} / 1.73 \mathrm{~m}^{2}$ for $<3$ months, or (ii) decrease in GFR by $\geq 35 \%$, or (iii) increase in serum creatinine by $>50 \%$ for $<3$ months [17], electrolyte imbalance requiring hospitalization during CRT, and ototoxicity.

\section{Statistical analysis}

All analyses were performed using the STATA/MP 14.1. Descriptive statistics, including mean \pm SD or median (range), were used for continuous variables. Differences between the three categories were compared using one-way analysis of variance (normal distribution) or Kruskal-Wallis test (non-normal distribution). Significant differences in proportions were determined using the Chi-square or Fisher's exact test, as appropriate. Receiver operating characteristic analysis was conducted to determine the cutoff CD of cisplatin $\left(\mathrm{mg} / \mathrm{m}^{2}\right)$ using the gold standard for predicting death status. Associated risk factors were initially screened using univariate and multivariate Cox regression analyses for OS with significance set at $p<0.10$. Identified variables were subsequently assessed using backward stepwise regression with significance set at $p \leq 0.05$. The final model included cisplatin CD during CRT and other significant factors. The goodness-of-fit assumption was assessed using the Hosmer-Lemeshow method with significance set at $p>0.05$. Cumulative hazard curves were modeled using the Kaplan-Meier method and compared using the Log-rank test. A p value of $<0.05$ indicated statistical significance.

\section{Results}

\section{Patient characteristics}

Overall 779 eligible patients with LA-NPC were identified from the database. Baseline patient and pathological characteristics according to $\mathrm{CD}$ of cisplatin are summarized in Table 1. Majority of the patients in this cohort (99\%) had WHO grades II and III disease. Approximately $50 \%$ patients underwent prophylactic feeding tube placement prior to CRT. Among those with a prophylactic feeding tube, $88 \%$ underwent percutaneous endoscopic gastrostomy, whereas $12 \%$ underwent nasogastric tube insertion. Patients who received low CD of cisplatin were significantly older at diagnosis $(p<0.001)$ and had poorer smoking status $(p=0.003)$, lower LN stage $(p=0.016)$, higher incidences of comorbidities, including cardiac disease $(p=0.009)$, diabetes mellitus $(p=0.014)$, and hypertension $(p=0.043)$, and higher baseline $\operatorname{CCr}(p<0.001)$ than other groups.

\section{Treatments and acute complications during chemoradiotherapy}

\section{Chemotherapy}


The mean CD of low-, intermediate-, and high-dose groups were 104, 207, and $287 \mathrm{mg} / \mathrm{m}^{2}$, respectively (Table 2). The intermediate $C D$ group received more weekly regimens than the low and high $C D$ groups $(p=0.031)$. Most patients in the high CD group $(98.5 \%)$ completed the planned cisplatin cycle. Only 60 patients in the low CD group (62\%) received adjuvant chemotherapy, whereas 363 (88\%) and 252 (93\%) patients in the intermediate and high CD groups received the same, respectively $(p<0.001)$. However, the high $C D$ group had a significantly lower mean $C D$ of adjuvant cisplatin than the other groups $(p=0.002)$.

\section{Radiotherapy}

Overall, 493 patients (63\%) concurrently received intensity-modulated radiation therapy (IMRT) with cisplatin as the definitive treatment, whereas $122(16 \%)$ and 149 (19\%) patients underwent 3D and 2D techniques, respectively. More patients in the intermediate CD group (72.5\%) received IMRT than the low $(63 \%)$ and high CD $(49 \%)$ groups $(\mathrm{p}<0.001$; Table 2$)$. However, those receiving a low CD of cisplatin had a significantly low mean actual RT dose $(p<0.001)$. Patients in the high CD group had longer duration of RT $(p=0.013)$, whereas RT delay was more common in low CD patients $(p=0.010)$.

\section{Acute complication and cisplatin-related toxicity}

Patients receiving a low $C D$ of cisplatin experienced higher rates of cisplatin interruption, delay, and termination of cisplatin $(p<0.001)$ compared with the intermediate and high CD groups (Table 2). Intermediate CD patients had the lowest incidence $(4 \%)$ of hospitalization during CRT $(p<0.001)$. Among those, in whom cisplatin was terminated, 31 (45.5\%) and 8 (9.9\%) in the low and intermediate CD groups subsequently received concurrent carboplatin and radiation, respectively. The low CD group had more patients with at least one acute complication (79.4\%) than the other groups.

Overall, cisplatin-related toxicity occurred in 306 patients (39.3\%), with the low CD group having the highest incidence (50.5\%; Table 2). The most common cisplatin-related toxicities included nephrotoxicity (26.4\%), grade 3-4 vomiting (4\%), grade 3-4 electrolyte imbalance (3.6\%), and grade 3-4 infection (including febrile neutropenia; 3.3\%; Supplement 2). Mean percent drop in $\mathrm{CCr}$ was significantly associated with higher CD of cisplatin $(p=0.001)$. Overall, $7 \%$ patients developed AKI during CRT, with the low CD group having the highest number (15.5\%; $p=0.002)$. Furthermore, the incidence of AKD was comparable between the high (38.2\%) and low (39.1\%) cisplatin groups but lower in the intermediate group $(28.7 \% ; p=0.038)$.

\section{Survival}

The median follow-up duration of the study was 59.4 months. Patients who received an intermediate CD of cisplatin had significantly longer median OS (64 months) than low and high (49.8 and 53.2 months, respectively) CD groups ( $p=0.015$; Figure $1 \mathrm{~A})$. Moreover, 5 -year OS among patients treated with low, intermediate, and high CD of cisplatin were $54 \%, 72 \%$, and $60 \%$, respectively $(p=0.004)$. The intermediate CD group (64\%) had a significantly higher 7-year OS than the low (51\%) and high (53\%) CD groups $(\mathrm{p}<$ 0.001). Subset analysis of patients who underwent IMRT showed no significant differences in OS among 
the cisplatin CD groups $(\mathrm{p}=0.584)$, whereas intermediate CD patients who underwent non-IMRT had significantly longer OS than the other groups $(p=0.016$; Figure 2$)$. Those who experienced cisplatin-related toxicity during CRT had significantly shorter OS ( $p=0.001$; Supplement 3 ). In addition, the intermediate CD patients had significantly longer RFS, DRFS, and LRFS than the low- and high-dose groups (Figure 1B-D).

Univariate and multivariate analyses of OS are summarized in Table 3. Univariate, but not multivariate, analysis showed that $\mathrm{CD}$ of cisplatin was significantly associated with OS. Multivariate analysis showed that age ${ }^{3} 65$, stage IVab at diagnosis, 2D/3D radiation technique, actual radiation dose of $<6600$ cGy, and hospitalization during CRT were associated with poor OS, whereas baseline BMI of ${ }^{3} 23 \mathrm{~kg} / \mathrm{m}^{2}$ and adjuvant chemotherapy were associated with longer OS.

\section{Discussion}

Patients who received an intermediate CD of cisplatin (151-250 mg/m²; mean $\left.207 \mathrm{mg} / \mathrm{m}^{2}\right)$ achieved the highest survival and lowest overall complications and cisplatin-related toxicities. However, only univariate analysis showed that cisplatin CD during CRT associated with OS. This suggests that cisplatin CD was not an independent prognostic factor for OS in locally advanced NPC. Therefore, the poorer survival in the low and high CD groups might have been affected by other related factors. Most of those who received a high CD of cisplatin ( $>250 \mathrm{mg} / \mathrm{m}^{2}$; mean $287 \mathrm{mg} / \mathrm{m}^{2}$ ) were treated with the standard recommended CD of cisplatin based on several pivotal phase III studies [5-7]. However, the high CD patients included herein developed significant more complications and cisplatin-related toxicities during treatment than the other groups. Though incidences of AKI were comparable among these groups, the high CD group had significantly higher incidences of AKD, cisplatin-related hospitalization, all cisplatin-related toxicities, and CCr decline after completion of CRT (Table 2). In contrast, patients who received low cisplatin CD ( $£ 150$ $\mathrm{mg} / \mathrm{m}^{2}$; mean $104 \mathrm{mg} / \mathrm{m}^{2}$ ) had poorer survival and more complications and cisplatin-related toxicities. Interestingly, none of the patients included herein satisfied the cisplatin ineligibility criteria for patients with head and neck cancer undergoing CRT in the Asia Pacific region [18]. However, some patients in this group could be considered high risk due to their age (>70 years) and ECOG of 2. Moreover, majority of the patients in the low CD group could have been cisplatin ineligible in the real world given that half of them suffered from cisplatin-related toxicity, whereas two-third experienced interruptions during cisplatin treatment. In addition, the present study showed that patients who suffered from cisplatin-related toxicity had poor OS. Therefore, we hypothesized that low survival observed in high CD group could have been attributed to cisplatin-related complications, which interfered with other significant treatments factors, such as treatment interruption, hospitalization, RT dose, and delay. However, it remains inconclusive whether the low survival observed in the low $C D$ group was indeed related to inadequate cisplatin $C D$ during CRT or intolerability to cisplatin that might have affected the primary treatment, RT.

A post-hoc analysis of a Chinese prospective phase III study involving 298 locally advanced NPC patients who underwent CRT reported that a cisplatin CD of ${ }^{3} 240 \mathrm{mg} / \mathrm{m}^{2}$ was not an independent prognostic factor for OS [9]. A larger retrospective study on 549 patients with locally advanced NPC who underwent 
concurrent cisplatin and IMRT from the same group revealed similar results [12]. Another retrospective Chinese study including 491 patients with locally advanced NPC who received with cisplatin and IMRT [10] showed that those who received a low cisplatin CD $\left(£ 100 \mathrm{mg} / \mathrm{m}^{2}\right)$ had poorer OS and DRFS than those who received intermediate ( 101 to $\left.\leq 200 \mathrm{mg} / \mathrm{m}^{2}\right)$ and high CDs $\left(>200 \mathrm{mg} / \mathrm{m}^{2}\right)$. These results are similar to those presented herein given that our intermediate $C D$ group received a mean cisplatin $C D$ of $207 \mathrm{mg} / \mathrm{m}^{2}$. However, none of the previous studies included a high CD group that received close to the recommended cisplatin CD $\left(280-300 \mathrm{mg} / \mathrm{m}^{2}\right)$ to which we could compared $[7,9,10,12]$. Moreover, none of these previous studies reported overall complications and cisplatin-related toxicities during CRT in each group.

Recently, induction chemotherapy with gemcitabine and cisplatin has prolonged OS and become the standard of care for treating locally advanced NPC [8]. Most patients (97\%) completed three cycles of induction chemotherapy, wherein cisplatin CD was $240 \mathrm{mg} / \mathrm{m}^{2}$. During CRT, patients in the induction group received significantly less median dose intensity than the standard group ( $200 \mathrm{vs.} 300 \mathrm{mg} / \mathrm{m}^{2}$; $p<0.001)$. A Chinese retrospective study showed no difference in OS among cisplatin CDs of more or less $160 \mathrm{mg} / \mathrm{m}^{2}$ during CRT for patients with locally advanced NPC receiving induction chemotherapy [19]. A larger study on 990 Chinese patients with NPC undergoing induction chemotherapy showed that a cisplatin CD of $\leq 100 \mathrm{mg} / \mathrm{m}^{2}$ was an independent prognostic factor for PFS and DRFS, but not for OS, among those who responded to induction chemotherapy [20]. Therefore, the optimal CD of cisplatin during CRT after completion of induction chemotherapy could perhaps be lower than that recommended $[7,8]$. Most studies, including our study, have suggested that the lowest cisplatin CD during CRT (at least $\left.150-200 \mathrm{mg} / \mathrm{m}^{2}\right)$ might not affect survival $[9,10,19,20]$.

Interestingly, the effect of cisplatin CD on OS had not been observed among patients who received IMRT but were more pronounced among those who received non-IMRT. Nonetheless, IMRT provides significantly better survival and lower serious toxicity compared to 2D and 3D techniques for the treatment of locally advanced NPC [21]. The effects of IMRT might override the benefit of adding it to concurrent chemotherapy for intermediate-risk (stage II and T3NOMO) NPC patients given that no improvement in OS had been observed [22,23]. Thus, a similar phenomenon may be observed herein for the variation of cisplatin $C D$.

Our study contains several limitations, especially selection bias of the actual CD of cisplatin administration during CRT due to retrospective nature of the study. To our knowledge, no phase III study has evaluated the optimal cisplatin CD during CRT for locally advanced NPC. All retrospective studies, including the present study, contain limitations, particularly selection bias of treating physicians, due to their retrospective nature. Therefore, in clinical practice, patients with locally advanced NPC might be receiving $\mathrm{CD}$ of cisplatin as recommended by the standard guideline or pivotal phase III randomized studies [5-8]. This may lead to unnecessary complications and toxicities, especially from cisplatin $[14,15]$. Moreover, these complications and toxicities may delay and/or affect radiation treatment, leading 
to poor survival. Thus, a randomized phase 3 study that would evaluate the optimal cisplatin CD during CRT for locally advanced NPC is warranted.

\section{Conclusions}

Though intermediate cisplatin CD $\left(151-250 \mathrm{mg} / \mathrm{m}^{2}\right)$ during CRT was not an independent prognostic factor for OS, it allowed for minimal overall complications and cisplatin-related toxicities without compromising survivals. Moreover, cisplatin-related toxicities during CRT were associated with poor OS. Thus, an intermediate dose should be considered as the optimal cisplatin CD concurrent with radiation for locally advanced NPC. Nonetheless, a randomized phase III study that would evaluate the optimal cisplatin CD during CRT for locally advanced NPC is warranted.

\section{Declarations}

Ethics approval and consent to participate: Ethics approval was obtained through the ethics committee at the Ramathibodi (ID 07-59-48), and Siriraj (ECI 149/2562) hospitals, Mahidol university, and Songklanagarind hospital (REC.61-007-14-1), Prince of Songkla University, and all patient information was de-identified.

Consent for publication: Not applicable

Availability of data and materials: Not applicable

Competing interests: The authors declare that they have no competing interests.

Funding: The study was funded by the Thailand Grand Challenge Program for Research University Network (RUN) under the Precision Medicine for Cancer project by the National Research Council of Thailand (NRCT) to Nuttapong Ngamphaiboon. The funding source has no involvement in the design of the study; data collection, analysis, and interpretation of data; and in writing the manuscript.

\section{Authors' contributions}

Study concepts: NN, PD

Study design: NN, PD

Data acquisition: $A D, J S, T D, R J, C J$

Quality control of data and algorithms: BS, PP

Data analysis and interpretation: PD, BS, PP, NN

Statistical analysis: NN, BS 
Manuscript preparation: NN

Manuscript editing: BS, CJ, PP, AD, PD

Manuscript review: All authors

\section{Acknowledgements}

The study was funded by the Thailand Grand Challenge Program for Research University Network (RUN) under the Precision Medicine for Cancer project by the National Research Council of Thailand (NRCT). The authors thank Chanaphat Pundorlha, and Sirichai Srigate for assisting with data collection and verification, and Ms. Dollapas Punpanich for statistical analysis.

\section{References}

1. Yu MC, Yuan JM. Epidemiology of nasopharyngeal carcinoma. Semin Cancer Biol 2002;12:421-9.

2. Tangjaturonrasme N, Vatanasapt $P$, Bychkov A. Epidemiology of head and neck cancer in Thailand. Asia Pac J Clin Oncol 2018;14:16-22.

3. Larbcharoensub N, Mahaprom K, Jiarpinitnun C, Trachu N, Tubthong N, Pattaranutaporn P, et al. Characterization of PD-L1 and PD-1 expression and CD8+ tumor-infiltrating lymphocyte in EpsteinBarr virus-associated nasopharyngeal carcinoma. Am J Clin Oncol 2018;41:1204-10.

4. Chan AT, Gregoire V, Lefebvre JL, Licitra L, Hui EP, Leung SF, et al. Nasopharyngeal cancer: EHNSESMO-ESTRO Clinical Practice Guidelines for diagnosis, treatment and follow-up. Ann Oncol 2012;23:vii83-5.

5. Al-Sarraf M, LeBlanc M, Giri PG, Fu KK, Cooper J, Vuong T, et al. Chemoradiotherapy versus radiotherapy in patients with advanced nasopharyngeal cancer: phase III randomized Intergroup study 0099. J Clin Oncol 1998;16:1310-7.

6. Chen L, Hu CS, Chen XZ, Hu GQ, Cheng ZB, Sun Y, et al. Concurrent chemoradiotherapy plus adjuvant chemotherapy versus concurrent chemoradiotherapy alone in patients with locoregionally advanced nasopharyngeal carcinoma: a phase 3 multicentre randomised controlled trial. Lancet Oncol 2012;13:163-71.

7. NCCN®. NCCN Clinical Practice Guidelines in Oncology (NCCN Guidelines ${ }^{\circledR}$ ) Head and Neck Cancers V3.2019. In.

8. Zhang Y, Chen L, Hu GQ, Zhang N, Zhu XD, Yang KY, et al. Gemcitabine and cisplatin induction chemotherapy in nasopharyngeal carcinoma. N Engl J Med 2019;381:1124-35.

9. Peng $\mathrm{H}$, Chen $\mathrm{L}$, Zhang Y, Li WF, Mao YP, Zhang F, et al. Prognostic value of the cumulative cisplatin dose during concurrent chemoradiotherapy in locoregionally advanced nasopharyngeal carcinoma: a secondary analysis of a prospective phase III clinical trial. Oncologist 2016;21:1369-76.

10. Guo SS, Tang LQ, Zhang L, Chen QY, Liu LT, Guo L, et al. The impact of the cumulative dose of cisplatin during concurrent chemoradiotherapy on the clinical outcomes of patients with advanced- 
stage nasopharyngeal carcinoma in an era of intensity-modulated radiotherapy. BMC Cancer 2015;15:977.

11. Danchaivijitr P, Ngamphaiboon N, Jiarpinitnun C, Sirachainan E, Pattaranutaporn P, Setakornnukul J. An optimal cumulative dose of cisplatin in chemoradiotherapy as a definitive treatment for nonmetastatic nasopharyngeal carcinoma: a retrospective multicenter study. Ann Oncol 2016;27.

12. Peng H, Chen L, Li WF, Guo R, Mao YP, Zhang Y, et al. The cumulative cisplatin dose affects the longterm survival outcomes of patients with nasopharyngeal carcinoma receiving concurrent chemoradiotherapy. Sci Rep 2016;6:24332.

13. Motwani SS, McMahon GM, Humphreys BD, Partridge AH, Waikar SS, Curhan GC. Development and validation of a risk prediction model for acute kidney injury after the first course of cisplatin. $J$ Clin Oncol 2018;36:682-8.

14. Faig J, Haughton M, Taylor RC, D'Agostino RB, Jr., Whelen MJ, Porosnicu Rodriguez KA, et al. Retrospective analysis of cisplatin nephrotoxicity in patients with head and neck cancer receiving outpatient treatment with concurrent high-dose cisplatin and radiotherapy. Am J Clin Oncol 2018;41:432-40.

15. Patimarattananan T, Pattaranutaporn, P, Unwanatham, N, Jiarpinitnun, C, Nongnuch, $A$, Ngamphaiboon, N. Risk and impact of renal impairment of locally advanced head and neck squamous cell carcinoma patients who received chemoradiotherapy with cisplatin. Ann Oncol 2019;30:v449-74.

16. Ostermann M, Joannidis M. Acute kidney injury 2016: diagnosis and diagnostic workup. Crit Care 2016;20:299.

17. Barry R, James MT. Guidelines for Classification of Acute Kidney Diseases and Disorders. Nephron 2015;131:221-6.

18. Ahn MJ, D'Cruz A, Vermorken JB, Chen JP, Chitapanarux I, Dang HQ, et al. Clinical recommendations for defining platinum unsuitable head and neck cancer patient populations on chemoradiotherapy: $A$ literature review. Oral Oncol 2016;53:10-6.

19. Lv JW, Qi ZY, Zhou GQ, He XJ, Chen YP, Mao YP, et al. Optimal cumulative cisplatin dose in nasopharyngeal carcinoma patients receiving additional induction chemotherapy. Cancer Sci 2018;109:751-63.

20. Liu SL, Sun XS, Yan JJ, Chen QY, Lin HX, Wen YF, et al. Optimal cumulative cisplatin dose in nasopharyngeal carcinoma patients based on induction chemotherapy response. Radiother Oncol 2019;137:83-94.

21. Lee AW, Ng WT, Chan LL, Hung WM, Chan CC, Sze HC, et al. Evolution of treatment for nasopharyngeal cancer-success and setback in the intensity-modulated radiotherapy era. Radiother Oncol 2014;110:377-84.

22. Zhang F, Zhang Y, Li WF, Liu X, Guo R, Sun Y, et al. efficacy of concurrent chemotherapy for intermediate risk NPC in the intensity-modulated radiotherapy era: a propensity-matched analysis. Sci Rep 2015;5:17378. 
23. Liu F, Jin T, Liu L, Xiang Z, Yan R, Yang H. The role of concurrent chemotherapy for stage II nasopharyngeal carcinoma in the intensity-modulated radiotherapy era: A systematic review and meta-analysis. PLoS One 2018;13:e0194733.

\section{Tables}

Table 1. Patient characteristics 
Patient characteristics

$N(\%)$

Median age (range) years

65

Sex

\begin{tabular}{c} 
Male \\
\hline Female \\
\hline Smoking status
\end{tabular}

Never

Ever

Median pack-year (range)

ECOG status

$0-1$
$\geq 2$

Baseline mean BMI ( \pm SD)
$<18.5$
$18.5-22.9$
$\geq 23$

57 (95\%)

$3(5 \%)$

$225(98.7 \%)$

$3(1.3 \%)$

$23.37 \pm 4.2$

$12(12.4 \%)$

$37(38.1 \%)$

$48(49.5 \%)$

WHO classification

I

T-stage

\begin{tabular}{cllll}
\hline T0-1 & $23(23.7 \%)$ & $96(23.4 \%)$ & $50(18.5 \%)$ & 0.156 \\
\hline T2-3 & $73(75.3 \%)$ & $305(74.2 \%)$ & $208(76.8 \%)$ & \\
\hline Tx & $1(1 \%)$ & $10(2.4 \%)$ & $13(4.8 \%)$ & \\
\hline LN Stage & & & & \\
\hline $0-1$ & $34(35.1 \%)$ & $140(34.1 \%)$ & $71(26.2 \%)$ & $0.016^{*}$ \\
\hline $2-3$ & $63(64.9 \%)$ & $263(64 \%)$ & $187(69 \%)$ &
\end{tabular}

Intermediate dose High dose p value $411(52.8 \%) \quad 271(34.8 \%)$

$48(11.9 \%)$

$11(4.2 \%)$

$<0.001^{*}$

$51[19-77] \quad 46[16-73] \quad<0.001 *$

0.243

$197(72.7 \%)$

$146(57 \%) \quad 0.003^{*}$

$110(43 \%)$

$14.13(5.25,22) \quad 0.946$

$23.47 \pm 4.15 \quad 23.37 \pm 4.17 \quad 0.952$

$25(6.1 \%) \quad 16(6 \%) \quad 0.199$

$181(44.3 \%) \quad 123(45.9 \%)$

$203(49.6 \%) \quad 129(48.1 \%)$

$0(0 \%) \quad 3(0.7 \%) \quad 7(2.7 \%) \quad 0.147$

$57(58.8 \%) \quad 217(54 \%) \quad 138(53.7 \%)$

$40(41.2 \%) \quad 182(45.3 \%) \quad 112(43.6 \%)$




\begin{tabular}{cllll} 
Patient characteristics & Low dose & Intermediate dose & High dose & p value \\
$\mathbf{N}(\%)$ & $\mathbf{9 7 ( 1 2 . 4 \% )}$ & $\mathbf{4 1 1}(\mathbf{5 2 . 8 \% )}$ & $\mathbf{2 7 1 ( 3 4 . 8 \% )}$ \\
\hline $\mathrm{Nx}$ & $0(0 \%)$ & $8(1.9 \%)$ & $13(4.8 \%)$
\end{tabular}

Stage at diagnosis

\begin{tabular}{lllll}
\hline I & $0(0 \%)$ & $1(0.2 \%)$ & $1(0.4 \%)$ & $0.029^{\star}$ \\
\hline II & $18(18.6 \%)$ & $70(17 \%)$ & $38(14 \%)$ & \\
\hline III & $36(37.1 \%)$ & $190(46.2 \%)$ & $124(45.8 \%)$ & \\
\hline Iva & $28(28.9 \%)$ & $104(25.3 \%)$ & $54(19.9 \%)$ & \\
\hline IVb & $15(15.5 \%)$ & $38(9.2 \%)$ & $41(15.1 \%)$ & \\
\hline Unknown & $0(0 \%)$ & $8(1.9 \%)$ & $13(4.8 \%)$ & \\
\hline Any comorbidity & $30(30.9 \%)$ & $92(22.4 \%)$ & $57(21 \%)$ & 0.127 \\
\hline Cardiac & $6(6.2 \%)$ & $10(2.4 \%)$ & $2(0.7 \%)$ & $0.009^{\star}$ \\
\hline Diabetes & $14(14.4 \%)$ & $37(9 \%)$ & $14(5.2 \%)$ & $0.014^{\star}$ \\
\hline Hyperlipidemia & $7(7.2 \%)$ & $20(4.9 \%)$ & $16(5.9 \%)$ & 0.622 \\
\hline Hypertension & $22(22.7 \%)$ & $68(16.5 \%)$ & $33(12.2 \%)$ & $0.043^{\star}$ \\
\hline Kidney Disease & $0(0 \%)$ & $3(0.7 \%)$ & $0(0 \%)$ & 0.260 \\
\hline Mean Baseline CCr $( \pm S D)$ & $81 \pm 27$ & $92 \pm 28$ & $129 \pm 29$ & $<0.001^{\star}$ \\
\hline Prophylactic feeding tube & $48(49.5 \%)$ & $201(48.9 \%)$ & $152(56.1 \%)$ & 0.169 \\
\hline
\end{tabular}

ECOG, Eastern Cooperative Oncology Group; BMI, body mass index; $\mathrm{CCr}$, creatinine clearance

Table. 2 Treatment and acute complications during chemoradiotherapy 


\section{Treatment}

$N(\%)$
Low dose

$97(12.4 \%)$
Intermediate High dose

dose

$411(52.8 \%)$
271

(34.8\%)

\section{Chemotherapy during CRT}

Mean cumulative dose of cisplatin during

CRT $\left(\mathrm{mg} / \mathrm{m}^{2}\right)( \pm \mathrm{SD})$
$103.62 \pm$

27.94
$206.9 \pm$

23.99
$286.54 \pm$

16.03 $p$ value

CRT regimen

Q1 week

Q3 week

Completed planned cycle during CRT

Median number of actual given cycles during CRT (range)

Weekly

Q3 week

Adjuvant chemotherapy regimen

Cisplatin-5FU

Carboplatin-5FU

No adjuvant chemotherapy

Mean cumulative dose of adjuvant cisplatin $\left(\mathrm{mg} / \mathrm{m}^{2}\right)( \pm \mathrm{SD})$
$3(1,3)$

$1(1,2)$
$11(11.3 \%)$

$86(88.7 \%)$

$1(1 \%)$
$26(6.3 \%)$

$385(93.7 \%)$

$154(37.5 \%)$
$32(11.8 \%) \quad 0.031^{*}$

239

$(88.2 \%)$

$\begin{array}{ll}267 & <0.001^{*}\end{array}$

$36(37.1 \%) \quad 345(83.9 \%)$

230

$(84.9 \%)$

$24(24.7 \%) \quad 18(4.4 \%) \quad 22(8.1 \%)$

$37(38.1 \%) \quad 48(11.7 \%) \quad 19(7 \%)$

$199.24 \pm$

93.3
$6(5,6)$

$2(2,3)$
$7(7,7)$

$3(3,3)$ $<0.001^{\star}$

$<0.001^{*}$ $<0.001 *$

\section{Radiotherapy (RT)}

Technique

IMRT

$3 D$

$2 \mathrm{D}$

Unknown

Mean actual dose (cGy) ( \pm SD)

Median duration (weeks) (range) 


\section{Treatment}

$N(\%)$

RT delay (>7 days)

Acute complication during CRT

\begin{tabular}{lllll}
\hline Cisplatin Interruption & $64(66 \%)$ & $186(45.3 \%)$ & $111(41 \%)$ & $<0.001^{*}$ \\
\hline Cisplatin Delay & $35(36.1 \%)$ & $75(18.2 \%)$ & $43(15.9 \%)$ & $<0.001^{*}$ \\
\hline Hospitalization & $11(11.5 \%)$ & $15(3.7 \%)$ & $30(11.1 \%)$ & $<0.001^{*}$ \\
\hline Termination of cisplatin & $66(68 \%)$ & $81(19.7 \%)$ & $13(4.8 \%)$ & $<0.001^{*}$ \\
\hline - Switch to carboplatin & $31(45.5 \%)$ & $8(9.9 \%)$ & $0(0 \%)$ & $<0.001^{*}$ \\
\hline At least 1 acute complication & $77(79.4 \%)$ & $191(46.5 \%)$ & 123 & $<0.001^{*}$ \\
\hline Cisplatin-related toxicity during CRT & & & $(45.4 \%)$ & \\
\hline All cisplatin-related toxicity & $49(50.5 \%)$ & $144(35 \%)$ & 113 & $0.012^{*}$ \\
\hline Mean percent dropped of CCr after CRT & $-8.79 \pm$ & $-18.23 \pm$ & $-24.03 \pm$ & $0.001^{*}$ \\
\hline completion $( \pm S D)$ & 40.09 & 26.6 & 24.68 & \\
\hline AKI & $15(15.5 \%)$ & $25(6.1 \%)$ & $14(5.2 \%)$ & $0.002^{*}$ \\
\hline AKD & $27(39.1 \%)$ & $98(28.7 \%)$ & $81(38.2 \%)$ & $0.038 *$ \\
\hline Hospitalization due to cisplatin & $10(10.3 \%)$ & $10(2.4 \%)$ & $23(8.5 \%)$ & $<0.001^{*}$ \\
\hline Treatment interruption due to cisplatin & $36(37.1 \%)$ & $71(17.3 \%)$ & $41(15.1 \%)$ & $<0.001^{*}$
\end{tabular}

CRT, chemoradiotherapy; 5FU, Fluorouracil; IMRT, intensity-modulated radiation therapy; AKI, acute kidney injury; AKD, acute kidney disease

Table 3. Univariate and multivariate analyses for overall survival 
Variables

\begin{tabular}{|c|c|c|c|c|}
\hline & \\
\hline & $\begin{array}{l}\text { Crude HR } \\
(95 \% \mathrm{Cl})\end{array}$ & p value & $\begin{array}{l}\text { Adjusted HR } \\
(95 \% \mathrm{Cl})\end{array}$ & $\mathrm{p}$ value \\
\hline Age $\geq 65$ years & $1.71(1.24,2.36)$ & $0.001^{\star}$ & $1.6(1.12,2.3)$ & $0.01 *$ \\
\hline Male & $0.78(0.61,1)$ & 0.052 & $0.73(0.54,1)$ & 0.052 \\
\hline Smoking & $1.66(1.32,2.09)$ & $<0.001^{\star}$ & $1.01(0.75,1.36)$ & 0.938 \\
\hline \multicolumn{5}{|l|}{ Stage at diagnosis } \\
\hline $1 / 11$ & Reference & 1 & Reference & 1 \\
\hline III & $1.45(0.99,2.14)$ & 0.057 & $1.48(0.98,2.22)$ & 0.061 \\
\hline IVab & $3.4(2.33,4.95)$ & $<0.001^{\star}$ & $3.35(2.26,4.96)$ & $<0.001^{*}$ \\
\hline \multicolumn{5}{|l|}{ BMI } \\
\hline $18.5-22.9$ & Reference & 1 & Reference & 1 \\
\hline$<18.5$ & $1.71(1.18,2.48)$ & $0.005^{\star}$ & $1.49(1,2.22)$ & 0.051 \\
\hline$\geq 23$ & $0.65(0.51,0.82)$ & $<0.001^{*}$ & $0.68(0.53,0.87)$ & $0.002^{\star}$ \\
\hline \multicolumn{5}{|l|}{ Radiation technique } \\
\hline IMRT & Reference & 1 & Reference & 1 \\
\hline $2 \mathrm{D} / 3 \mathrm{D}$ & $2.05(1.64,2.57)$ & $<0.001^{\star}$ & $1.57(1.18,2.09)$ & $0.002^{*}$ \\
\hline RT delay & $1.46(1.14,1.88)$ & $0.003^{*}$ & $1.08(0.81,1.45)$ & 0.586 \\
\hline \multicolumn{5}{|l|}{ Actual dose of radiation (cGy) } \\
\hline 6600 & Reference & 1 & Reference & 1 \\
\hline$<6600$ & $2.56(1.56,4.17)$ & $<0.001^{\star}$ & $1.89(1.08,3.33)$ & $0.026^{\star}$ \\
\hline \multicolumn{5}{|l|}{ Cisplatin schedule during CRT } \\
\hline Q1 week & Reference & 1 & & \\
\hline Q3 week & $1.36(0.78,2.38)$ & 0.284 & & \\
\hline \multicolumn{5}{|l|}{ Cisplatin dose during CRT } \\
\hline Intermediate & Reference & 1 & Reference & 1 \\
\hline Low & $1.46(1.04,2.06)$ & $0.028^{*}$ & $0.86(0.58,1.27)$ & 0.444 \\
\hline High & $1.36(1.07,1.72)$ & $0.013^{\star}$ & $1.3(0.99,1.7)$ & 0.057 \\
\hline $\begin{array}{l}\text { Chemotherapy interruption during } \\
\text { CRT }\end{array}$ & $1.33(1.07,1.66)$ & $0.011^{\star}$ & $1.33(0.99,1.78)$ & 0.056 \\
\hline
\end{tabular}




\begin{tabular}{|c|c|c|c|c|}
\hline \multirow[t]{2}{*}{ Variables } & \multicolumn{2}{|l|}{ Univariate } & \multicolumn{2}{|l|}{ Multivariate } \\
\hline & $\begin{array}{l}\text { Crude HR } \\
(95 \% \mathrm{Cl})\end{array}$ & $\mathrm{p}$ value & $\begin{array}{l}\text { Adjusted HR } \\
(95 \% \mathrm{Cl})\end{array}$ & $\mathrm{p}$ value \\
\hline Chemotherapy delay during CRT & $1.52(1.18,1.96)$ & $0.001^{\star}$ & $0.93(0.67,1.3)$ & 0.685 \\
\hline Hospitalization during CRT & $2.39(1.72,3.32)$ & $<0.001^{\star}$ & $1.57(1.08,2.28)$ & $0.019 *$ \\
\hline $\begin{array}{l}\text { Chemotherapy termination during } \\
\text { CRT }\end{array}$ & $1.17(0.9,1.52)$ & 0.244 & & \\
\hline Adjuvant chemotherapy & $0.63(0.46,0.85)$ & $0.002^{\star}$ & $0.59(0.41,0.84)$ & $0.003^{\star}$ \\
\hline All cisplatin-related complications & $1.44(1.15,1.79)$ & $0.001^{\star}$ & $1.16(0.89,1.51)$ & 0.274 \\
\hline AKD & $1.21(0.93,1.58)$ & 0.149 & & \\
\hline AKI & $1.91(1.33,2.74)$ & $<0.001^{*}$ & & \\
\hline
\end{tabular}

$\mathrm{RT}$, radiotherapy; CRT, chemoradiotherapy; IMRT, intensity-modulated radiation therapy; AKI, acute kidney injury; AKD, acute kidney disease

\section{Figures}



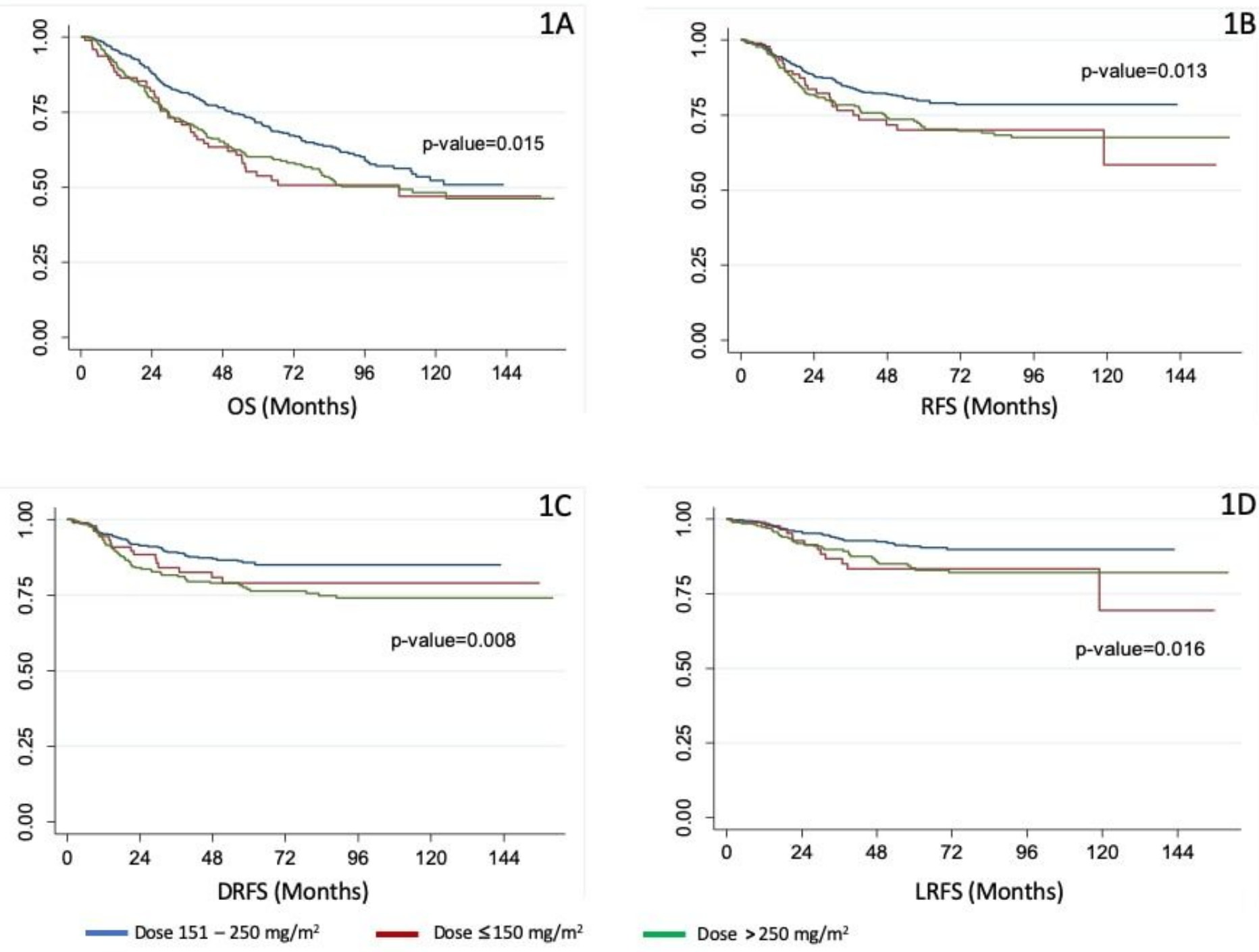

\section{Figure 1}

Patient survival based on cumulative dose of cisplatin $(\mathrm{mg} / \mathrm{m} 2)$ during chemoradiotherapy. 1A Overall survival (OS), 1B Recurrence-free survival (RFS), 1C distant recurrence-free survival (DRFS), 1D Locoregional recurrence-free survival (LRFS) 


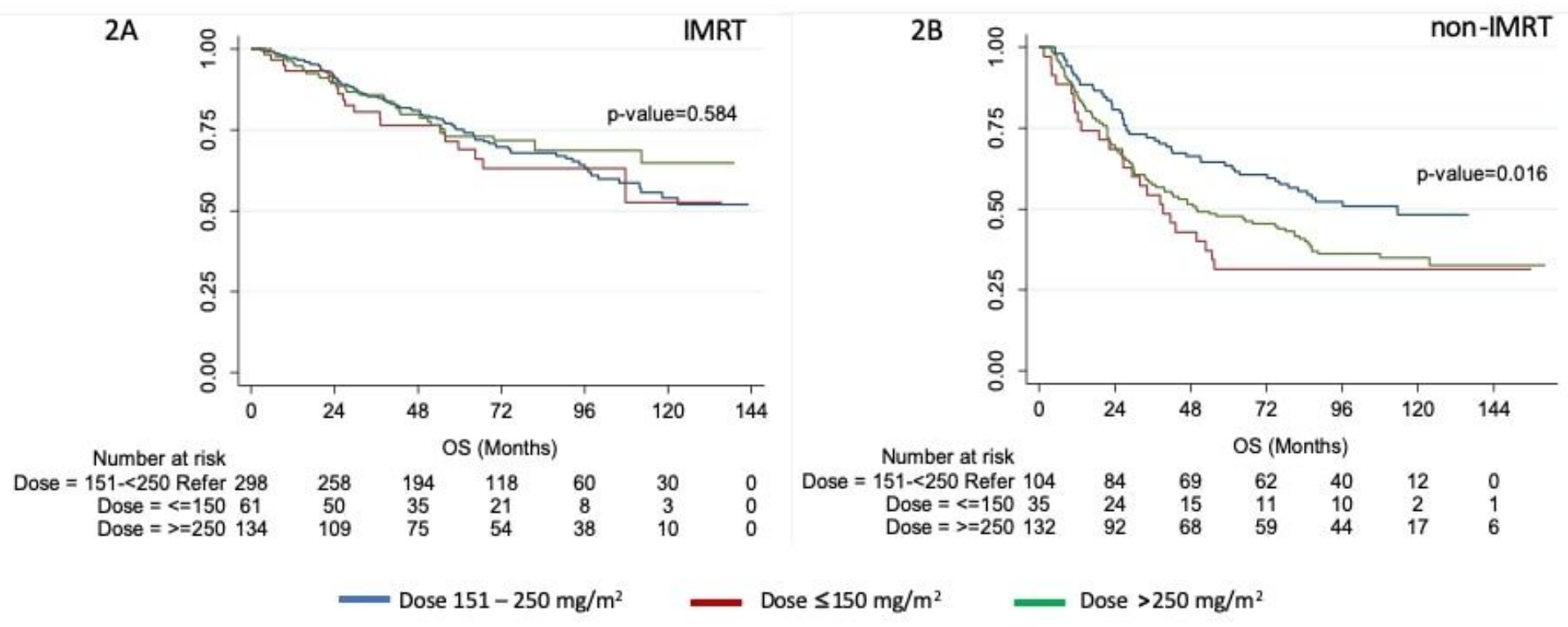

Figure 2

Overall survival using the RT technique. 2A intensity-modulated radiation therapy, 2B non-intensitymodulated radiation therapy 